\title{
Effect of enhanced external counterpulsation treatment on renal function in cardiac patients
}

\author{
Prajej Ruangkanchanasetr ${ }^{1 *}$, Nithi Mahanonda², Ongkarn Raungratanaamporn², Piyanuj Ruckpanich², \\ Chagriya Kitiyakara ${ }^{3}$, Amnart Chaiprasert', Surawat Adirekkiat4, Dollapas Punpanich', Somlak Vanavanan', \\ Anchalee Chittamma ${ }^{5}$ and Thanom Supaporn ${ }^{1}$
}

\begin{abstract}
Background: Enhanced external counterpulsation (EECP) enhances coronary perfusion and reduces left ventricular afterload. However, the role of EECP on renal function in cardiac patients is unknown. Our aim was to assess renal function determined by serum cystatin $C$ in cardiac patients before and after EECP treatment.

Methods: A prospective observational longitudinal study was conducted in order to evaluate renal function using serum cystatin C (Cys C) and estimated glomerular filtration rate (GFR) after 35 sessions of EECP treatment in 30 patients with chronic stable angina and/or heart failure. The median (IQR) time for follow-up period after starting EECP treatment was 16 (10-24) months.

Results: Cys C significantly declined from $1.00(0.78-1.31)$ to $0.94(0.77-1.27) \mathrm{mg} / \mathrm{L}(\mathrm{p}<0.001)$ and estimated GFR increased from $70.47(43.88-89.41)$ to $76.27(49.02-91.46) \mathrm{mL} / \mathrm{min} / 1.73 \mathrm{~m}^{2}(p=0.006)$ after EECP treatment. Subgroup analysis showed that patients with baseline GFR $<60 \mathrm{~mL} / \mathrm{min} / 1.73 \mathrm{~m}^{2}$ or NT-proBNP $>125 \mathrm{pg} / \mathrm{mL}$ had a significant decrease in Cys $C$ when compared to other groups $(p<0.01)$.

Conclusions: The study demonstrated that EECP could improve long-term renal function in cardiac patients especially in cases with declined renal function or with high NT-proBNP.

Trial registration: The study was registered in the clinical trial as International Standard Randomized Controlled Trial Number ISRCTN11560035.
\end{abstract}

Keywords: Angina, Chronic kidney disease, Cystatin C, Glomerular filtration rate, Heart failure

\section{Background}

A close relationship between the function of the heart and the kidneys has long been recognized. The bidirectional nature of this interaction forms an important concept in the classification of the cardiorenal syndrome. A decrease in cardiac function could adversely impact renal function [1]. Impaired renal function is independently associated with increased risk for cardiovascular diseases, hospitalization for congestive heart failure (CHF) and cardiovascular death $[2,3]$. Therefore, therapies that improve cardiac function might have potentially beneficial effects on renal perfusion and glomerular filtration.

\footnotetext{
* Correspondence: prajej@gmail.com

${ }^{1}$ Division of Nephrology, Department of Medicine, Phramongkutklao Hospital, 315 Rajavithi Road, Rajathevi, Bangkok 10400, Thailand

Full list of author information is available at the end of the article
}

EECP is a nonpharmacologic therapy for outpatients with angina pectoris and CHF $[4,5]$. EECP is based on the principle of diastolic augmentation to increase coronary flow while simultaneously decreasing systolic afterload. During diastole, cuffs inflate sequentially from the calves proximally to raise diastolic aortic pressure and theoretically increase coronary perfusion pressure. At the same time, increased venous return would result in increased cardiac output by Starling mechanism. Then the cuffs are rapidly decompressed at the onset of systole creating negative pressure that decreases cardiac afterload [6,7].

EECP is a low risk procedure, approved by US Food and Drug Administration for refractory angina and CHF $[5,8,9]$. Nevertheless, the impact of EECP treatment on renal function in cardiac patients has not been well documented. The objective of this study was to assess the

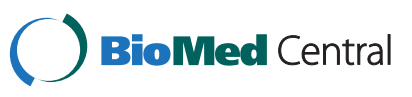


effects of EECP treatment on renal function in patients with chronic stable angina and/or CHF.

\section{Methods}

\section{Study design}

This study was a prospective observational longitudinal study. Outpatients at cardiology clinic of Piyavate hospital were included during January 2007 and November 2009. Inclusion criteria were (1) age 18 years or more (2) having chronic stable angina and/or CHF. Exclusion criteria were (1) having unstable angina or acute myocardial infarction or decompensated CHF in the preceding one month (2) undergoing coronary angiography or coronary artery bypass grafting in the preceding one month (3) blood pressure $>180 / 110 \mathrm{mmHg}$ (4) severe symptomatic peripheral vascular disease and (5) GFR $<15 \mathrm{~mL} / \mathrm{min} /$ $1.73 \mathrm{~m}^{2}$. This study was approved by the Institutional Review Board of Piyavate hospital and written informed consent was obtained from each patient. The study was registered in the clinical trial as International Standard Randomized Controlled Trial Number ISRCTN11560035.

After recruitment, all patients underwent a standard round of 35 sessions of 1-hr daily EECP treatment using EECP machine (Vasomedical, Westbury, New York, USA) over a period of 7-8 weeks. Demographics, baseline characteristics, clinical presentations and laboratory findings were collected in the case record forms. Prior to EECP treatment, fasting blood samples were collected and then also immediately collected at the end of $35^{\text {th }}$ session as well as every $2-3$ month interval.

The samples were centrifuged at $5000 \mathrm{rpm}$ for $5 \mathrm{mi}-$ nutes at $4{ }^{\circ} \mathrm{C}$ and the supernatant was separated and stored at $-30^{\circ} \mathrm{C}$ until analysis. Renal function was evaluated by changes in Cys $\mathrm{C}$ and estimated GFR using an equation that combined both serum creatinine and cystatin $C$ with age, sex and race [10]. This equation has been shown to have improved accuracy compared to the estimated GFR equations that used either one of these markers alone [10].

$\mathrm{Cr}$ was measured based on isotope-dilution mass spectrometry standardized enzymatic method using the SRM 967 as control. The mean concentrations with the acceptable ranges of 2 SRM levels were $65.4(66.5 \pm 1.9)$ and $343.9(346.2 \pm 7.3) \mu \mathrm{mol} / \mathrm{L}$, respectively. Cys $\mathrm{C}$ was measured by a particle-enhanced immunonephelometric assay using a BN Prospec nephelometer (Siemens Healthcare Diagnostics, Germany). The assay range is $0.23 \mathrm{mg} / \mathrm{L}$ to $8.00 \mathrm{mg} / \mathrm{L}$. Within-run precision was assessed at the low $(0.92 \mathrm{mg} / \mathrm{L})$ and high $(1.97 \mathrm{mg} / \mathrm{L})$ concentrations which yielded coefficients of variation $(\mathrm{CoV})$ of $1.92 \%$ and $1.08 \%$ and day-to-day $\mathrm{CoV}$ of $2.03 \%$ and $1.28 \%$, respectively. NTproBNP was also evaluated before and after 35 sessions of EECP treatment. NT-proBNP was determined by a sandwich immunoassay using Elecsys proBNP 2010 (Roche
Diagnostics, Basel, Switzerland). The analytical range extends from $5-35,000 \mathrm{pg} / \mathrm{mL}$.

\section{Sample size calculation}

The sample size was calculated based on the report of Werner et al. [11] showing that the pre-EECP GFR and post-EECP GFR of 12 patients in the control group were $68 \pm 16$ and $84 \pm 22 \mathrm{~mL} / \mathrm{min} / 1.73 \mathrm{~m}^{2}$. An estimated number of 26 patients would give $90 \%$ power for a statistically significant difference of the GFR outcome between pre and post EECP. To account for a $10 \%$ dropout rate, about 30 patients were enrolled.

\section{Statistical analysis}

All statistical analysis was performed using STATA version 9.2 (StataCorp LP, Texas, USA). Continuous data were summarized as mean (SD) or median (IQR). For normally distributed data, paired T- test was used and Wilcoxon signed ranks test for non-normally distributed data. Categorical data were expressed as frequencies and percentages. All $\mathrm{p}$ values were two-sided. A $\mathrm{p}$-value of $<0.05$ was considered statistically significant.

\section{Results}

A total of 30 patients with chronic angina (23/30, 76.7\%) and/or CHF $(7 / 30,23.3 \%)$ were recruited to the prospective observational longitudinal study during January 2007 and November 2009. The median (IQR) follow up time was 16 (10-24) months after starting EECP treatment. Baseline characteristics, clinical parameters and laboratory findings are shown in Table 1 and Table 2 . Majority of patients were male $(76.7 \%, 23 / 30)$. The study patients had mean (SD) age of 69.1 (13.8) years and body mass index of $26.1(4.9) \mathrm{kg} / \mathrm{m}^{2}$. Median (IQR) systolic blood pressure $[(122,113-133) \mathrm{mmHg}]$, diastolic blood pressure $[(75,70-77) \mathrm{mmHg}]$ and heart rate $[(70,61-75)$ beats/min] were within normal limits.

Of the study patients, 29 (96.7\%) patients had coronary artery disease before EECP treatment followed by hypertension in 27 (90\%), diabetes in $23(76.7 \%)$, stroke in 8 (26.7\%), CHF in 7 (23.3\%) and peripheral artery disease in 4 (13.3\%), respectively. Ten (33.3\%) patients had smoking history in which 7 (70\%) patients were past smokers and $3(30 \%)$ patients were current smokers. The majority $(90 \%, 27 / 30)$ of patients had undergone coronary angiography before EECP treatment. Twelve patients (40\%) underwent percutaneous coronary intervention and six patients $(20 \%)$ underwent coronary artery bypass grafting. Of 7 patients with prior history of CHF, 6 had $\mathrm{EF}<40 \%$ consistent with systolic heart failure due to ischemia and 1 had diastolic dysfunction. According to recent medications before EECP treatment, $93.3 \%$ (28/30) of patients received statin therapy, 90\% (27/30) aspirin or clopidogrel, 76.7\% (23/30) angiotensin-converting enzyme inhibitors (ACEI) 


\section{Table 1 Demographic and baseline characteristics of study patients $(\mathbf{n}=30)$}

\begin{tabular}{|c|c|}
\hline Characteristics & \\
\hline Age (yr), mean (SD) & $69.1(13.8)$ \\
\hline Male & $23(76.7 \%)$ \\
\hline Body mass index $\left(\mathrm{kg} / \mathrm{m}^{2}\right)$, mean (SD) & $26.1(4.9)$ \\
\hline \multicolumn{2}{|l|}{ Clinical history } \\
\hline Coronary artery disease & $29(96.7 \%)$ \\
\hline Hypertension & $27(90.0 \%)$ \\
\hline Diabetes & $23(76.7 \%)$ \\
\hline Stroke & $8(26.7 \%)$ \\
\hline Angina pectoris & $23(76.7 \%)$ \\
\hline Heart failure & $7(23.3 \%)$ \\
\hline Peripheral artery disease & $4(13.3 \%)$ \\
\hline Smoking status & $10(33.3 \%)$ \\
\hline Past smoker & $7(70.0 \%)$ \\
\hline Current smoker & $3(30.0 \%)$ \\
\hline \multicolumn{2}{|l|}{ Previous procedures } \\
\hline Coronary angiography & $27(90.0 \%)$ \\
\hline Percutaneous coronary intervention & $12(40.0 \%)$ \\
\hline Coronary artery bypass grafting & $6(20.0 \%)$ \\
\hline \multicolumn{2}{|l|}{ Medication } \\
\hline Statin & $28(93.3 \%)$ \\
\hline Aspirin or Clopidogrel & $27(90.0 \%)$ \\
\hline ACE inhibitor or ARB & $23(76.7 \%)$ \\
\hline Beta-blocker & $19(63.3 \%)$ \\
\hline Nitrate & $17(56.7 \%)$ \\
\hline Calcium-channel blocker (Diltiazem or Verapamil) & $10(33.3 \%)$ \\
\hline \multicolumn{2}{|l|}{ Laboratory findings, mean (SD) } \\
\hline Hemoglobin (g/dL) & $12.9(1.8)$ \\
\hline Albumin (g/dL) & $4.2(0.4)$ \\
\hline Cholesterol (mg/dL) & $146.0(27.0)$ \\
\hline HDL cholesterol (mg/dL) & $49.5(12.2)$ \\
\hline LDL cholesterol (mg/dL) & $77.8(19.6)$ \\
\hline Triglyceride (mg/dL) & $103.3(48.7)$ \\
\hline Glucose (mg/dL) & $118.3(27.6)$ \\
\hline Hemoglobin $\mathrm{A}_{1} \mathrm{C}(\%)$ & $7.5(1.3)$ \\
\hline LVEF (\%) & $55.0(17.9)$ \\
\hline
\end{tabular}

or angiotensin receptor blockers (ARB), 63.3\% (19/30) beta-blockers, 56.7\% (17/30) nitrate and 33.3\% (10/30) calcium channel blockers including diltiazem and verapamil. The doses of ACEI, ARB and beta-blockers were unchanged during EECP treatment and no new medications were added during follow- up.

Baseline laboratory findings showed that the mean (SD) of hemoglobin [12.9 (1.8) g/dL], albumin [4.2 (0.4) g/dL] and lipid profiles including cholesterol [146.0 (27.0) $\mathrm{mg} / \mathrm{dL}]$, triglyceride [103.3 (48.7) mg/dL], HDL cholesterol [49.5 (12.2) mg/dL], LDL cholesterol [77.8 (19.6) mg/dL] were within normal limits except fasting blood sugar [118.3 (27.6) $\mathrm{mg} / \mathrm{dL}$ ] and hemoglobin $\mathrm{A}_{1} \mathrm{C}$ [7.5 (1.3) \%] were higher than normal limits. The mean (SD) left ventricular ejection fraction (LVEF) was 55.0 (17.9) \% before EECP treatment. The median (IQR) Cr, GFR, Cys $\mathrm{C}$ and NT-proBNP before EECP treatment were 1.02 (0.84-1.36) $\mathrm{mg} / \mathrm{dL}, 70.47$ (43.88-89.41) $\mathrm{mL} / \mathrm{min}$ per $1.73 \mathrm{~m}^{2}, 1.0(0.78$ 1.31) $\mathrm{mg} / \mathrm{L}$ and 244 (120-1067) $\mathrm{pg} / \mathrm{mL}$, respectively.

During EECP treatment period, there was no withdrawal of EECP treatment or any serious adverse effect occurred. Only two patients reported the development of skin blebs which resolved after supportive treatment and none of the patients had clinical heart failure. After EECP treatment, systolic blood pressure, diastolic blood pressure and heart rate were not significantly changed. Overall, there was an improvement in cardiac symptoms [NYHA Classification Class I/II/III/IV (n): Baseline 0/15/ 13/2 versus Follow-up 13/16/1/0 ( $<<0.001)]$. New York Heart Association Classification Class was improved by at least 1 class in 26 patients (86.7\%).

In order to evaluate renal function, Cys $\mathrm{C}$ and estimated GFR were used as the primary outcomes. At the end of $35^{\text {th }}$ sessions of EECP treatment, Cys $C$ was not significantly different from the baseline $[(0.91,0.77-1.39) \mathrm{mg} / \mathrm{L}$ versus $(1.00,0.78-1.31) \mathrm{mg} / \mathrm{L}, \mathrm{p}=0.421, \mathrm{n}=27$ (3 missing data at the end of EECP because of technical error)], but Cys $C$ declined significantly at the end of the followup period $[(1.00,0.78-1.31) \mathrm{mg} / \mathrm{L}$ versus $(0.94,0.77$ 1.27) $\mathrm{mg} / \mathrm{L}, \mathrm{p}<0.001, \mathrm{n}=30$ ]. Similarly, GFR was not significantly different at the end of $35^{\text {th }}$ session of EECP treatment $\left[(70.47,43.88-89.41) \mathrm{mL} / \mathrm{min} / 1.73 \mathrm{~m}^{2}\right.$ versus (83.46, 47.26-97.51) $\mathrm{mL} / \mathrm{min} / 1.73 \mathrm{~m}^{2}, \mathrm{p}=0.075, \mathrm{n}=27$ ] but GFR significantly increased at the end of the follow-up period [(70.47, 43.88-89.41) $\mathrm{mL} / \mathrm{min} / 1.73 \mathrm{~m}^{2}$ versus (76.27, 49.02-91.46) $\mathrm{mL} / \mathrm{min} / 1.73 \mathrm{~m}^{2}, \mathrm{p}=0.006, \mathrm{n}=30$ ] (Table 2).

In the present study, the majority of patients had coronary artery disease, hypertension and diabetes before EECP treatment and the estimated GFR was also lower than normal population suggesting that several patients had chronic kidney disease (CKD) at baseline. According to the National Kidney Foundation-Kidney Disease Outcomes Quality Initiative (NKF-K/DOQI) workgroup, stage 3 CKD was defined as the presence of GFR $<60 \mathrm{~mL} / \mathrm{min} /$ $1.73 \mathrm{~m}^{2}$ for at least 3 months [12]. Among patients with stage $3 \mathrm{CKD}$, most had negative or trace proteinuria and were presumed to have decreased GFR due to nephrosclerosis or decreased renal perfusion. Only one patient had nephrotic range proteinuria and another patient had moderate proteinuria and were both presumed to have diabetic nephropathy. Healthy individuals typically have NT-proBNP $\leq 125 \mathrm{pg} / \mathrm{mL}[13,14]$. Thus, the parameters including GFR $<60 \mathrm{~mL} / \mathrm{min} / 1.73 \mathrm{~m}^{2}$ and 
Table 2 Outcomes of study patients after EECP treatment

\begin{tabular}{|c|c|c|c|}
\hline \multirow[t]{3}{*}{ Characteristics } & \multicolumn{3}{|c|}{ Median (IQR) } \\
\hline & Baseline & End of $35^{\text {th }}$ session & Follow-up \\
\hline & $(n=30)$ & $(n=27)$ & $(n=30)$ \\
\hline \multirow[t]{2}{*}{ Systolic blood pressure (mm Hg) } & 122 & 120 & 130 \\
\hline & $(113-133)$ & $(110-130)$ & $(120-130)$ \\
\hline$p$-value & & $0.139^{\mathrm{a}}$ & $0.473^{b}$ \\
\hline \multirow[t]{2}{*}{ Diastolic blood pressure (mm Hg) } & 75 & 70 & 78 \\
\hline & $(70-77)$ & $(70-80)$ & $(70-80)$ \\
\hline$p$-value & & $0.839^{a}$ & $0.431^{b}$ \\
\hline \multirow[t]{2}{*}{ Heart rate (beats/min) } & 70 & 68 & 71 \\
\hline & $(61-75)$ & $(59-80)$ & $(63-80)$ \\
\hline$p$-value & & $0.628^{a}$ & $0.071^{b}$ \\
\hline \multirow[t]{2}{*}{ Creatinine (mg/dL) } & 1.02 & 0.97 & 1.01 \\
\hline & $(0.84-1.36)$ & $(0.8-1.34)$ & $(0.85-1.36)$ \\
\hline$p$-value & & $0.115^{\mathrm{a}}$ & $0.156^{b}$ \\
\hline \multirow[t]{2}{*}{ GFR (mL/min per $\left.1.73 \mathrm{~m}^{2}\right)$} & 70.47 & 83.46 & 76.27 \\
\hline & $(43.88-89.41)$ & $(47.26-97.51)$ & $(49.02-91.46)$ \\
\hline$p$-value & & $0.075^{\mathrm{a}}$ & $0.006^{b * *}$ \\
\hline \multirow[t]{2}{*}{ Cystatin C (mg/L) } & 1.00 & 0.91 & 0.94 \\
\hline & $(0.78-1.31)$ & $(0.77-1.39)$ & $(0.77-1.27)$ \\
\hline$p$-value & & $0.421^{a}$ & $<0.001^{b_{* *}}$ \\
\hline \multirow[t]{2}{*}{ NT-proBNP (pg/mL) } & 244 & 200 & 210 \\
\hline & $(120-1067)$ & $(70-653)$ & $(123-398)$ \\
\hline$p$-value & & $0.416^{\mathrm{a}}$ & $0.425^{b}$ \\
\hline
\end{tabular}

${ }^{\mathrm{a}}$ End of $35^{\text {th }}$ session versus baseline, calculated using Wilcoxon signed ranks test.

${ }^{b}$ Follow-up versus baseline, calculated using Wilcoxon signed ranks test.

${ }^{* *}$ )indicated statistically significant $p$-value less than 0.01 .

NT-proBNP $>125 \mathrm{pg} / \mathrm{mL}$ were used as cut -off points for further analysis.

Subgroup analysis showed that patients with baseline GFR $<60 \mathrm{~mL} / \mathrm{min} / 1.73 \mathrm{~m}^{2}$ had significant decrease in Cys C [1.55 (1.26-1.85) mg/L versus 1.4 (1.14-1.65) mg/ $\mathrm{L}, \mathrm{p}=0.004$ ] and corresponding increase in GFR at follow-up after EECP therapy [43.59 (39.1-53.29) $\mathrm{mL} /$ $\mathrm{min} / 1.73 \mathrm{~m}^{2}$ versus $47.52(41.1-55.76) \mathrm{mL} / \mathrm{min} / 1.73 \mathrm{~m}^{2}$, $\mathrm{p}=0.003]$.

There was a significant inverse correlation between GFR and NT-proBNP at baseline (Figure 1). In addition, subgroup with NT-proBNP > $125 \mathrm{pg} / \mathrm{mL}$ at baseline had significant decrease in Cys $\mathrm{C}$ at follow-up [1.26 (0.94$1.68) \mathrm{mg} / \mathrm{L}$ versus $1.14(0.88-1.51) \mathrm{mg} / \mathrm{L}, \mathrm{p}=0.001]$ and correspondingly, had significant increase in GFR [59.43 (43.31-74.47) $\mathrm{mL} / \mathrm{min} / 1.73 \mathrm{~m}^{2}$ versus 62.26 (46.97$83.18) \mathrm{mL} / \mathrm{min} / 1.73 \mathrm{~m}^{2}, \mathrm{p}=0.001$ ] (Table 3). Of the $30 \mathrm{pa}-$ tients, 10 patients had a decrease in NT-proBNP $>30 \%$ from baseline at the end of EECP treatment. Among these patients, Cys $\mathrm{C}$ was significantly decreased in follow-up period [1.01 (0.81-1.31) mg/L versus 0.97 (0.69-1.20) mg/L, $\mathrm{p}=0.017]$ whereas estimated GFR showed a trend to increase $(\mathrm{p}=0.051)($ Table 3$)$.

\section{Discussion}

EECP has been shown to be an effective therapy for patients with angina and CHF $[8,15]$ who were not candidates for revascularization [16]. The safety of EECP treatment was demonstrated in left ventricular dysfunction patients with minor adverse effects such as skin blebs in the present study $[16,17]$. The prospective evaluation of enhanced external counterpulsation in congestive heart failure $(\mathrm{PEECH})$ study showed that EECP treatment improved exercise tolerance and quality of life [18]. Similar to previous study of Loh et al. [19], the New York Heart Association Classification Class was improved by at least 1 class in 26 patients $(86.7 \%)$.

In the present study, the majority of patients had diabetes and hypertension co-existing with advanced heart disease. The baseline GFR $\left(70.47 \mathrm{~mL} / \mathrm{min} / 1.73 \mathrm{~m}^{2}\right)$ was lower than normal population. In such patients, several mechanisms of chronic heart impairment including 


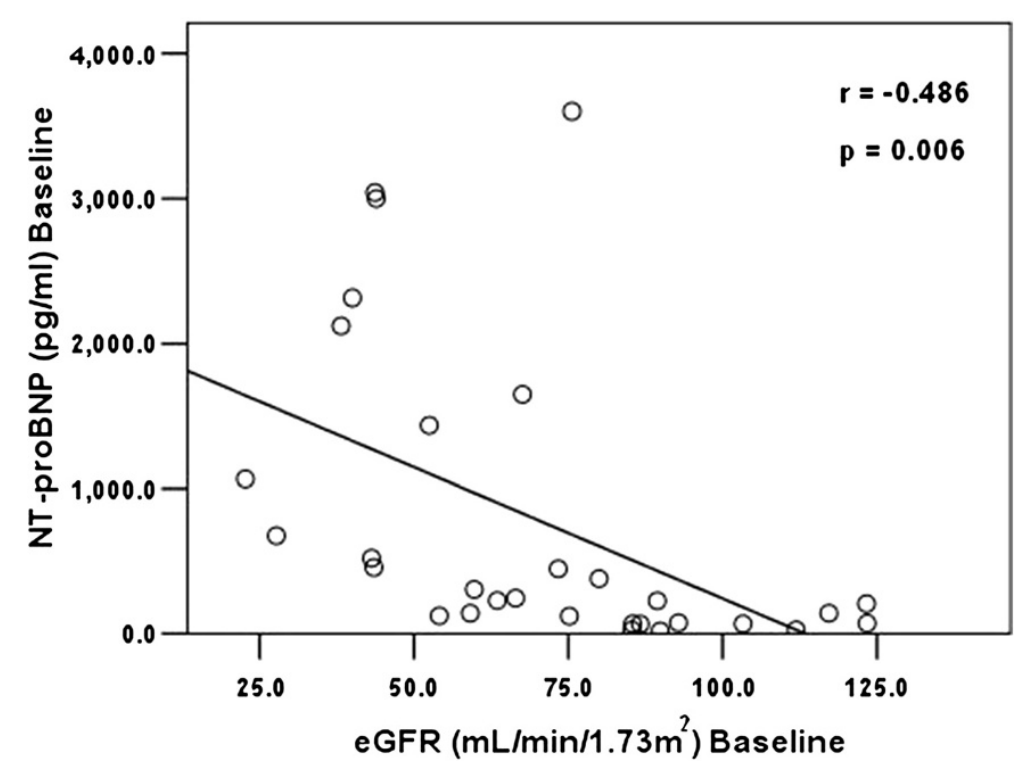

Figure 1 Scatter plot shows relationship between GFR and NT-proBNP at baseline.

systolic dysfunction, increased venous congestion and activation of neurohormonal axis might lead to decrease renal function [1]. Previous study has shown that EECP treatment was able to increase GFR by $24 \%$ and renal plasma flow by $21-30 \%$ in healthy volunteers due to decreased renal vascular resistance, plasma renin activity and endothelin $[11,20]$. However, there was no study to assess the benefit of EECP treatment on renal function in cardiac patients. Therefore, we conducted the first study to evaluate the immediate and long term effects of EECP treatment on renal function in patients with chronic stable angina and/or CHF.

We found that EECP treatment did not have immediate effect on renal function but improved long term renal function during 16-month follow-up period. The beneficial effect of EECP was greater for those with diminished renal function $\left(\right.$ GFR $<60 \mathrm{~mL} / \mathrm{min} / 1.73 \mathrm{~m}^{2}$ ) or high NT-proBNP $(>125 \mathrm{pg} / \mathrm{mL})$ at baseline. Among these patients, Cys C decreased approximately $0.12 \mathrm{mg} / \mathrm{L}$ which corresponded to increased Cys C-based GFR of $6 \mathrm{~mL} / \mathrm{min} / 1.73 \mathrm{~m}^{2}$ [10]. This finding was consistent with an increase in estimated GFR after EECP therapy using the combined creatinine and Cys $C$ equation (70.47 to $76.27 \mathrm{~mL} / \mathrm{min}$ per $1.73 \mathrm{~m}^{2}$ ). Regarding two-way interactions of the heart and the kidney, the small improvement in GFR after EECP in this study could benefit for the cardiac function and vice-versa.

Presently, there is consensus on an age-independent NT-proBNP for evaluation of CHF $[13,14]$ and the percentage change of NT-proBNP after therapy is an important predictor of cardiovascular outcomes [21,22]. In the present study, patients with $>30 \%$ decline of NT-proBNP at the end of $35^{\text {th }}$ session had significantly improved renal function. This was similar to previous study that demonstrated NT-proBNP reduction $>30 \%$ after therapy to be the best cut-off value for defining the risk of re-hospitalization and mortality [23].

The beneficial effects of EECP on cardiac function have been shown to involve changes in neurohormonal regulation, improved systolic function, endothelial function, and collateral vessel formation $[8,24]$. It has been proposed that chronic exposure of coronary and peripheral arterial bed to the augmented blood flow and increased shear forces produced by EECP could lead to increased endothelial cell production of nitric oxide (NO), prostacyclin [25] as well as lead to the development of collateral vessels through the release of angiogenic growth factors [26,27] and increased circulating endothelial progenitor cells [28]. In experimental dogs, EECP increased the density of microvessels in the infarcted regions significantly compared with the control group [29]. The formation of new blood vessels(angiogenesis), enhancement of collateral development from preexisting vessels(arteriogenesis), or an improvement in endovascular function [29] may help explain the delay in benefits observed on renal function and the long lasting effects of EECP [15]. Improvement of the results of myocardial perfusion test on EECP therapy had been shown to persist for 3 years [30]. This sustained improvement in cardiovascular function could indirectly account for the long term effects of EECP on GFR observed in our study. The close relationship between the function of the heart and the kidney is supported by the observation that the GFR was 
Table 3 Change of Cys C and GFR after EECP treatment $(n=30)$

\begin{tabular}{|c|c|c|c|}
\hline \multirow[t]{2}{*}{ Characteristics } & \multicolumn{3}{|c|}{ Median (IQR) } \\
\hline & Baseline & End of $35^{\text {th }}$ session & Follow-up \\
\hline \multicolumn{4}{|l|}{ Estimated GFR } \\
\hline $\mathrm{GFR}<60 \mathrm{~mL} / \mathrm{min} / 1.73 \mathrm{~m}^{2}(\mathrm{n}=12)$ & $n=12$ & $n=9$ & $\mathrm{n}=12$ \\
\hline \multirow[t]{2}{*}{ Cystatin C (mg/L) } & 1.55 & 1.44 & 1.4 \\
\hline & $(1.26-1.85)$ & $(1.2-1.59)$ & $(1.14-1.65)$ \\
\hline$p$-value & & $0.173^{\mathrm{a}}$ & $0.004^{b * *}$ \\
\hline \multirow[t]{2}{*}{ GFR (mL/min per $\left.1.73 \mathrm{~m}^{2}\right)$} & 43.59 & 46.11 & 47.52 \\
\hline & $(39.1-53.29)$ & $(42.06-47.26)$ & $(41.1-55.76)$ \\
\hline$p$-value & & $0.374^{a}$ & $0.003^{b * *}$ \\
\hline $\mathrm{GFR} \geq 60 \mathrm{~mL} / \mathrm{min} / 1.73 \mathrm{~m}^{2}(\mathrm{n}=18)$ & $\mathrm{n}=18$ & $\mathrm{n}=18$ & $\mathrm{n}=18$ \\
\hline \multirow[t]{2}{*}{ Cystatin C (mg/L) } & 0.83 & 0.82 & 0.8 \\
\hline & $(0.73-0.89)$ & $(0.72-0.91)$ & $(0.63-0.92)$ \\
\hline$p$-value & & $0.931^{\mathrm{a}}$ & $0.052^{b}$ \\
\hline \multirow[t]{2}{*}{ GFR (mL/min per $\left.1.73 \mathrm{~m}^{2}\right)$} & 86.05 & 92.34 & 88.81 \\
\hline & $(75.16-103.3)$ & (83.46-105.38) & $(81.22-109.79)$ \\
\hline$p$-value & & $0.157^{\mathrm{a}}$ & $0.124^{b}$ \\
\hline \multicolumn{4}{|l|}{ NT-proBNP } \\
\hline NT-proBNP $\leq 125 \mathrm{pg} / \mathrm{mL}(\mathrm{n}=9)$ & $n=9$ & $n=9$ & $n=9$ \\
\hline \multirow[t]{2}{*}{ Cystatin C (mg/L) } & 0.78 & 0.82 & 0.81 \\
\hline & $(0.76-0.87)$ & $(0.72-0.87)$ & $(0.77-0.87)$ \\
\hline$p$-value & & $0.906^{\mathrm{a}}$ & $0.553^{b}$ \\
\hline \multirow[t]{2}{*}{ GFR (mL/min per $\left.1.73 \mathrm{~m}^{2}\right)$} & 86.69 & 88.75 & 83.11 \\
\hline & $(85.28-92.84)$ & $(83.46-105.23)$ & $(81.42-96.54)$ \\
\hline$p$-value & & $0.374^{a}$ & $0.767^{b}$ \\
\hline NT-proBNP > 125 pg/mL $(n=20)$ & $n=20$ & $\mathrm{n}=17$ & $n=20$ \\
\hline \multirow[t]{2}{*}{ Cystatin C (mg/L) } & 1.26 & 1.16 & 1.14 \\
\hline & $(0.94-1.68)$ & $(0.84-1.53)$ & $(0.88-1.51)$ \\
\hline$p$-value & & $0.523^{a}$ & $0.001^{b * *}$ \\
\hline \multirow[t]{2}{*}{ GFR (mL/min per $\left.1.73 \mathrm{~m}^{2}\right)$} & 59.43 & 57.66 & 62.26 \\
\hline & $(43.31-74.47)$ & $(46.11-91.46)$ & $(46.97-83.18)$ \\
\hline$p$-value & & $0.246^{\mathrm{a}}$ & $0.001^{b * *}$ \\
\hline NT-proBNP decline $>30 \%$ from baseline $(n=10)$ & $n=10$ & $n=9$ & $\mathrm{n}=10$ \\
\hline \multirow[t]{2}{*}{ Cystatin C (mg/L) } & 1.01 & 1.00 & 0.97 \\
\hline & $(0.81-1.31)$ & $(0.77-1.2)$ & $(0.69-1.2)$ \\
\hline$p$-value & & $0.594^{a}$ & $0.017^{b *}$ \\
\hline \multirow[t]{2}{*}{ GFR $\left(\mathrm{mL} / \mathrm{min}\right.$ per $\left.1.73 \mathrm{~m}^{2}\right)$} & 65.53 & 66.87 & 66.46 \\
\hline & $(43.68-79.98)$ & $(47.26-93.98)$ & $(49.02-91.85)$ \\
\hline$p$-value & & $0.214^{a}$ & $0.051^{\mathrm{b}}$ \\
\hline
\end{tabular}

Values are Median $\left(25^{\text {th }}-75^{\text {th }}\right.$ percentile). $p$ - value was calculated with the use of Wilcoxon signed ranks test, ${ }^{\text {a }}$ End of $35^{\text {th }}$ session versus baseline; ${ }^{\text {b }}$ Last follow-up versus baseline.

$\left.{ }^{*}\right)$ indicated statistically significant $p$-value less than $0.05 ;\left(^{* *}\right)$ indicated statistically significant $p$-value less than 0.01 .

inversely related to NT-proBNP level. As this relationship is bidirectional, the small improvement in GFR after EECP observed in this study could be a result of benefits on cardiac function and/or vice-versa.
The effects on renal function were not apparent using serum $\mathrm{Cr}$ or Cr-based GFR equation (data not shown). Serum $\mathrm{Cr}$ can be affected by many factors such as muscle mass and protein intake. It is possible that improvement in 
cardiac function after EECP might have led to improved nutritional status and masked the small improvement in renal function when serum $\mathrm{Cr}$ is used as a marker. Previous studies have suggested that $\mathrm{Cys} C$ is a more accurate and sensitive marker of GFR compared to $\mathrm{Cr}$ in diabetic and non-diabetic patients [31] as well as being less influenced by age, gender, weight, dietary protein intake and muscle mass, which obscure changes in Cr-based GFR $[32,33]$. Moreover, changes in Cys $C$ levels can be used to more accurately predict changes in GFR than changes in Cr [34]. Thus, Cys C was used to evaluate renal function in the study. Although Cys $\mathrm{C}$ is less dependent on factors such as age, sex, race and body mass index when compared to creatinine-based GFR estimation, it can be affected by other factors such as body composition (lean mass), thyroid dysfunction, cancer and left ventricular mass [35-38]. It is possible that GFR -independent factors could account for decreases in serum cystatin in some individuals, but these factors were not apparent during the follow-up of our patients and were unlikely to account for the changes in serum cystatin $C$ in the group as a whole. In addition, we evaluated the effects of EECP on renal function using GFR estimating equation which employed Cys $\mathrm{C}$ in combination with $\mathrm{Cr}$, age, sex and race [10]. This equation has recently been shown to be more accurate than equations using either marker alone $[10,39,40]$ and has been recommended as the optimal equation by experts for assessing CKD [40].

This study has several limitations. This was an observational, small-sized study without a parallel control group or sham EECP group (defined as suboptimal counterpulsation). Routine measurement of LVEF after treatment was not available. We used endogenous markers of renal function rather than formal clearance studies. This would tend to underestimate any changes in renal function especially if the GFR was relatively well preserved. The effects on renal function by EECP as a group were modest, and the clinical significance of such minor improvement in GFR on cardiovascular or renal outcome is uncertain. Given the within-person individual variability of renal function measurements [41,42] and the small size of the study, it may be possible that the apparent statistically significant differences may be explained by chance. On the other hand, it is also possible that if a more sensitive method to detect GFR was available or if only patients with renal impairment or high NT-proBNP were studied, the larger improvement might be detected.

The results from this study provide support for larger comparative studies between EECP and placebo measuring Cys $\mathrm{C}$ level and GFR in well-matched groups to be done in the future in order to determine the benefits of EECP treatment. In particular, the observation that the beneficial effect of EECP was greater for patients with diminished renal function and for those with elevated NT-proBNP very much supports the need for such studies in patients with moderate to severe reduction in GFR or in those with congestive heart failure.

\section{Conclusions}

EECP is a safe, effective and feasible treatment for cardiac patients. This is the first study to demonstrate that EECP did not show the immediate effect on renal function but could augment the renal function as measured by Cys $\mathrm{C}$ and estimated GFR in cardiac patients after long term follow up, especially in the groups with decreased GFR or high NT-proBNP.

\section{Abbreviations}

ACEl: Angiotensin-converting enzyme inhibitors; ARB: Angiotensin receptor blockers; CHF: Congestive heart failure; Cr: Plasma creatinine; Cys C: Serum cystatin C; EECP: Enhanced external counterpulsation; GFR: Glomerular filtration rate; LVEF: Left ventricular ejection fraction.

\section{Competing interests}

The authors declare that they have no competing interests.

\section{Authors' contributions}

PR designed the study and wrote the manuscript; NM and OR recruited the patients; PR supervised the EECP treatment; CK helped in the design of the study and in writing manuscript; AC and DP performed the statistical analyses; SA participated in the collection of data and data analysis; SV and AC measured plasma creatinine, serum cystatin C and NT-proBNP; TS critically revised the manuscript. All authors read and approved the final manuscript.

\section{Acknowledgements}

The authors are grateful to Varunee Desakorn and Vipa Thanachartwet, Department of Clinical Tropical Medicine, Faculty of Tropical Medicine, Mahidol University, Bangkok, Thailand, for their valuable suggestions, comments and revising this manuscript for publication. We also thank Runglawan Khwandee, all staff and nurses in cardiology clinic, Piyavate Hospital for assistance in caring patients.

\section{Author details}

'Division of Nephrology, Department of Medicine, Phramongkutklao Hospital, 315 Rajavithi Road, Rajathevi, Bangkok 10400, Thailand. 'Perfect Heart Institute, Piyavate Hospital, Bangkok, Thailand. ${ }^{3}$ Division of Nephrology, Department of Medicine, Ramathibodi Hospital, Bangkok, Thailand. ${ }^{4}$ Division of Nephrology, Department of Medicine, Piyavate Hospital, Bangkok, Thailand. ${ }^{5}$ Division of Clinical Chemistry, Department of Pathology, Ramathibodi Hospital, Bangkok, Thailand.

Received: 11 February 2013 Accepted: 4 September 2013 Published: 11 September 2013

\section{References}

1. Ronco C, Haapio M, House AA, Anavekar N, Bellomo R: Cardiorenal syndrome. J Am Coll Cardiol 2008, 52:1527-1539.

2. Anavekar NS, McMurray JJV, Velazquez EJ, Solomon SD, Kober L, Rouleau JL, White HD, Nordlander R, Maggioni A, Dickstein K, Zelenkofske S, Leimberger JD, Califf RM, Pfeffer MA: Relation between renal dysfunction and cardiovascular outcomes after myocardial infarction. N Engl J Med 2004, 351:1285-1295.

3. Hillege HL, Nitsch D, Pfeffer MA, Swedberg K, McMurray JJV, Yusuf S, Granger CB, Michelson EL, Östergren J, Cornel JH, de Zeeuw D, Pocock S, van Veldhuisen DJ: Renal function as a predictor of outcome in a broad spectrum of patients with heart failure. Circulation 2006, 113:671-678.

4. Arora RR, Chou TM, Jain D, Fleishman B, Crawford L, McKiernan T, Nesto RW: The multicenter study of enhanced external counterpulsation (MUST-EECP): effect of EECP on exercise-induced myocardial ischemia and angina episodes. J Am Coll Cardiol 1999, 33:1833-1840. 
5. Michaels AD, McCullough PA, Soran OZ, Lawson WE, Barsness GW, Henry TD, Linnemeier G, Ochoa A, Kelsey SF, Kennard ED: Primer: practical approach to the selection of patients for and application of EECP. Nat Clin Pract CardiovasC Med 2006, 3:623-632

6. Conti CR: EECP-enhanced external counterpulsation. J Am Coll Cardiol 1999, 33:1841-1842

7. Mielniczuk L, da Silva LB, Haddad H: Enhanced external counterpulsation in ischemic heart disease and congestive heart failure. CMAJ 2004, 170:1223-1224.

8. Arora RR, Shah AG: Enhanced external counterpulsation: a new modality in the treatment of angina and heart failure. $J$ Cardiovasc Pharmacol Ther 2006, 11:271-273.

9. Soran O: Treatment options for refractory angina pectoris: enhanced external counterpulsation therapy. Curr Treat Options Cardiovasc Med 2009, 11:54-60.

10. Stevens LA, Coresh J, Schmid CH, Feldman HI, Froissart M, Kusek J, Rossert J, Lente FV, Bruce RD III, Zhang YL, Greene T, Levey AS: Estimating GFR using serum cystatin $C$ alone and in combination with serum creatinine: a pooled analysis of 3418 individuals with CKD. Am J Kidney Dis 2008, 51:395-406

11. Werner D, Tragner P, Wawer A, Porst H, Daniel WG, Gross P: Enhanced external counterpulsation: a new technique to augment renal function in liver cirrhosis. Nephrol Dial Transplant 2005, 20:920-926.

12. National Kidney Foundation: K/DOQI clinical practice guidelines for chronic kidney disease: evaluation, classification, and stratification. Am J Kidney Dis 2002, 39:S1-S266.

13. Hildebrandt $\mathrm{P}, \mathrm{Collinson} \mathrm{PO}$ : Amino-terminal pro-B-type natriuretic peptide testing to assist the diagnostic evaluation of heart failure in symptomatic primary care patients. Am J Cardiol 2008, 101(suppl):25A-28A

14. Zaphiriou A, Robb S, Murray-Thomas T, Mendez G, Fox K, McDonagh T, Hardman SM, Dargie HJ, Cowie MR: The diagnostic accuracy of plasma BNP and NTproBNP in patients referred from primary care with suspected heart failure: results of the UK natriuretic peptide study. Eur J Heart Fail 2005, 7:537-541.

15. Silver MA: Mechanisms and evidence for the role of enhanced external counterpulsation in heart failure management. Curr Heart Fail Rep 2006, 3:25-32

16. Manchanda A, Soran O: Enhanced external counterpulsation and future directions. J Am Coll Cardiol 2007, 50:1523-1531.

17. McCullough PA, Silver MA, Kennard ED, Kelsey SF, Michaels AD: Impact of body mass index on outcomes of enhanced external counterpulsation therapy. Am Heart J 2006, 151:139.e9-139.e13.

18. Feldman AM, Silver MA, Francis GS, Abbottsmith CW, Fleishman BL, Soran O, de Lame PA, Varricchione T: Enhanced external counterpulsation improves exercise tolerance in patients with chronic heart failure. J Am Coll Cardiol 2006, 48:1198-1205

19. Loh PH, Cleland JGF, Louis AA, Kennard ED, Cook JF, Caplin JL, Barsness GW Lawson WE, Soran OZ, Michaels AD: Enhanced external counterpulsation in the treatment of chronic refractory angina: a long-term follow-up outcome from the International Enhanced external counterpulsation Patient Registry. Clin Cardiol 2008, 31:159-164.

20. Werner D, Schneider M, Weise M, Nonnast-Daniel B, Daniel WG: Pneumatic external counterpulsation: a new noninvasive method to improve organ perfusion. Am J Cardiol 1999, 84:950-952.

21. Moertl D, Hammer A, Huelsmann M, Pacher R, Berger R: Prognostic value of sequential measurements of amino-terminal prohormone of B-type natriuretic peptide in ambulatory heart failure patients. Eur J Heart Fail 2008, 10:404-411.

22. DeFilippi CR, Christenson RH, Gottdiener JS, Kop WJ, Seliger SL: Dynamic cardiovascular risk assessment in elderly people. The role of repeated $\mathrm{N}$-terminal pro-B-type natriuretic peptide testing. J Am Coll Cardiol 2010, 55:441-450.

23. Verdiani V, Ognibene A, Rutili MS, Lombardo C, Bacci F, Terreni A, Nozzoli C: NT-ProBNP reduction percentage during hospital stay predicts long-term mortality and readmission in heart failure patients. $J$ Cardiovasc Med 2008, 9:694-699.

24. Bonetti PO, Holmes DR, Lerman A, Barsness GW: Enhanced external counterpulsation for ischemic heart disease. What's behind the curtain? J Am Coll Cardiol 2003, 41:1918-1925.

25. Cohn PF: EECP-new data on possible mechanisms of action. Eur Heart $J$ 2001, 22:1363-1364
26. Fujita M: Angiogenic therapy by coronary collateral recruitment and arteriogenesis. In Myocardial ischemia and preconditioning. 1st edition. Edited by Dhalla NS, Takeda N, Singh M, Lukas A. Norwell, MA: Kluwer Academic Publishers; 2003:13-22.

27. Buschmann EE, Utz W, Pagonas N, Schulz-Menger J, Busjahn A, Monti J, Maerz W, le Noble F, Thierfelder L, Dietz R, Klauss V, Gross M, Buschmann IR: Improvement of fractional flow reserve and collateral flow by treatment with external counterpulsation (Art.Net.-2 Trial). Eur J Clin Invest 2009, 39:866-875.

28. Barsheshet A, Hod H, Shechter M, Sharabani-Yosef O, Rosenthal E, Barbash IM, Matetzky S, Tal R, Bentancur AG, Sela BA, Nagler A, Leor J: The effects of external counter pulsation therapy on circulating endothelial progenitor cells in patients with angina pectoris. Cardiology 2008, 110:160-166.

29. Wu G, Du Z, Hu C, Zheng Z, Zhan C, Ma H, Fang D, Ahmed KT, Laham RJ, Hui JCK, Lawson WE: Angiogenic effects of long-term enhanced external counterpulsation in a dog model of myocardial infarction. Am J Physiol Heart Circ Physiol 2006, 290:H248-H254.

30. Masuda D, Nohara R, Hirai T, Kataoka K, Chen LG, Hosokawa R, Inubushi M, Tadamura E, Fujita M, Sasayama S: Enhanced external counterpulsation improved myocardial perfusion and coronary flow reserve in patients with chronic stable angina. Eur Heart J 2001, 22:1451-1458.

31. Dharnidharka VR, Kwon C, Stevens G: Serum cystatin C is superior to serum creatinine as a marker of kidney function: a meta-analysis. Am J Kidney Dis 2002, 40:221-226.

32. Baxmann AC, Ahmed MS, Marques NC, Menon VB, Pereira AB, Kirsztajn GM, Heilberg IP: Influence of muscle mass and physical activity on serum and urinary creatinine and serum cystatin C. Clin J Am Soc Nephrol 2008, 3:348-354.

33. Séronie-Vivien $S$, Delanaye $P$, Piéroni $L$, Mariat $C$, Froissart $M$, Cristol JP: SFBC "Biology of renal function and renal failure" working group: csystatin C: current position and future prospects. Clin Chem Lab Med 2008, 46:1664-1686

34. Perkins BA, Nelson RG, Ostrander BEP, Blouch KL, Krolewski AS, Myers BD, Warram $\mathrm{JH}$ : Detection of renal function decline in patients with diabetes and normal or elevated GFR by serial measurements of serum cystatin C concentration: results of a 4-year follow-up study. J Am Soc Nephrol 2005, 16:1404-1412.

35. Macdonald J, Marcora S, Jibani M, Roberts G, Mick Kumwenda M, Glover R, Barron J, Lemmey A: GFR estimation using cystatin $C$ is not independent of body composition. Am J Kidney Dis 2006, 48:712-719.

36. Wiesli P, Schwegler B, Spinas GA, Schmid C: Serum cystatin C is sensitive to small changes in thyroid function. Clin Chim Acta 2003, 338:87-90.

37. Nakai K, Kikuchi M, Fujimoto K, Kaneko Y, Omori S, Nakai K, Suwabe A: Serum levels of cystatin $C$ in patients with malignancy. Clin Exp Nephrol 2008, 12:132-139.

38. Patel PC, Ayers CR, Murphy SA, Peshock R, Khera A, de Lemos JA, Balko JA Gupta S, Mammen PPA, Drazner MH, Markham DW: Association of cystatin $C$ with left ventricular structure and function. The Dallas heart study. Circ Heart Fail 2009, 2:98-104.

39. Inker LA, Schmid CH, Tighiouart $H$, Eckfeldt JH MD, Feldman $H$, Greene $T$, Kusek JW, Manzi J, Van Lente F, Lucy Zhang YL, Coresh J, Andrew L: Estimating glomerular filtration rate from serum creatinine and cystatin C. N Engl J Med 2012, 367:20-9.

40. Eknoyan G, Lameire N, Eckardt KU, Kasiske BL, Wheeler DC, Levin A Stevens PE, Bilous RW, Lamb EJ, Coresh J, Levey AS, de Francisco ALM, Riella MC, de Jong PE, Shlipak MG, Griffith KE, Wang H, Hemmelgarn BR, White CT, Iseki K, Winearls CG: KDIGO 2012 clinical practice guideline for the evaluation and management of chronic kidney disease. Kidney Int 2013, Suppl 3:5-14.

41. Sikaneta T, Abdolell M, Taskapan H, Roscoe J, Fung J, Nagai G, Ting RH, Ng P, Wu G, Oreopoulos D, Tam PY: Variability in CKD stage in outpatients followed in two large renal clinics. Int Urol Nephrol 2012, 44:1461-1466.

42. Onuigbo MA, Onuigbo NT: Variability in CKD stage in outpatients followed in two large renal clinics: implications for CKD trials and the status of current knowledge of patterns of CKD to ESRD progression. Int Urol Nephrol 2012, 44:1589-1590.

doi:10.1186/1471-2369-14-193

Cite this article as: Ruangkanchanasetr et al:: Effect of enhanced external counterpulsation treatment on renal function in cardiac patients. BMC Nephrology 2013 14:193. 